\title{
Empresários mais ricos do Brasil: a ignorância, o cinismo e a ganância que matam
}

Empresários mais ricos do Brasil: a ignorância, o cinismo e a ganância que matam $^{1}$

Los empresarios más ricos de Brasil: ignorancia, el cinismo y la avaricia que matan

Les entrepreneurs les plus riches du Brésil : l'ignorance, le cynisme et l'avidité qui tuent

Richest businessmen in Brazil: ignorance, cynicism and greed that kill.

\section{Gaudêncio Frigotto}

\section{(2) OpenEdition}

Journals

\section{Edição electrónica}

URL: http://journals.openedition.org/espacoeconomia/10852

DOI: 10.4000/espacoeconomia.10852

ISSN: 2317-7837

\section{Editora}

Núcleo de Pesquisa Espaço \& Economia

\section{Refêrencia eletrónica}

Gaudêncio Frigotto, «Empresários mais ricos do Brasil: a ignorância, o cinismo e a ganância que matam », Espaço e Economia [Online], 17 | 2020, posto online no dia 07 abril 2020, consultado o 22 abril 2020. URL : http://journals.openedition.org/espacoeconomia/10852 ; DOI : https://doi.org/ 10.4000/espacoeconomia.10852 


\title{
Empresários mais ricos do Brasil: a ignorância, o cinismo e a ganância que matam
}

\author{
Empresários mais ricos do Brasil: a ignorância, o cinismo e a ganância que \\ matam $^{1}$ \\ Los empresarios más ricos de Brasil: ignorancia, el cinismo y la avaricia que \\ matan \\ Les entrepreneurs les plus riches du Brésil : l'ignorance, le cynisme et l'avidité \\ qui tuent \\ Richest businessmen in Brazil: ignorance, cynicism and greed that kill.
}

\section{Gaudêncio Frigotto}

“Duas coisas são infinitas: o universo e a estupidez humana. Mas, em relação ao universo, ainda não tenho certeza absoluta."

Albert Einstein

1 Escrevo este pequeno texto referindo-me, sobretudo, ao grupo de empresários multimilionários que financiaram ou os que apoiaram a campanha O Brasil não pode parar. Mas, também, às mentes débeis e humanamente cínicas do núcleo ideológico e metafísico do governo federal que a encomendaram. Desdenhar da ciência, das orientações da Organização Mundial de Saúde, dos depoimentos dramáticos dos médicos, enfermeiros, fisioterapeutas, bombeiros etc. não é só, como Einstein afirma, uma infinita estupidez humana, mas a participação ativa e consentida em milhares de mortes que podem ser evitadas.

2 Dados da Revista Forbes mostram que, em 2019, o número de bilionários no Brasil aumentou aproximadamente 50\%. "Segundo o ranking anual da Forbes, o país tem 58 bilionários, cuja fortuna somou 179,7 bilhões de dólares. No ano passado, eram 42 pessoas com mais de 1 bilhão de dólares no bolso"2. Estes megaempresários são herdeiros de uma cultura cuja riqueza não se fez por seu trabalho, mas, no passado, 
matando os índios como se fossem animais; em seguida, por quase quatrocentos anos, acumulando fortuna com o trabalho escravo e a compra e venda de seres humanos como gado. Estas práticas não acabaram. A dizimação dos índios continua, assim como a escravidão, que foi abolida formalmente, mas continua nas relações sociais e econômicas. Como herdeiros desta cultura, a alta burguesia empresarial brasileira montou uma das sociedades de capitalismo dependente das mais desiguais do mundo. Uma desigualdade que vem sendo mostrada globalmente neste momento dramático da humanidade, causado pela Covid-19.

3 As fortunas dos atuais megaempresários, do campo e da cidade, resultam de três estratégias que se potenciam, como mostrou Caio Prado Junior (1966), antes mesmo das relações capitalistas se generalizarem no Brasil. A primeira se afirma na superexploração e espoliação do trabalhador, gerando uma assimetria descomunal entre os ganhos do patronato e do trabalhador; a segunda, é a estratégia de preferir a compra da cópia, em vez de investir em ciência, tecnologia e inovação; por fim, tomam dinheiro subsidiado pelo Estado, o que dá origem às dívidas externa e interna. Por este meio, concorrem deslealmente com médios e pequenos empresários, que são os que geram mais empregos, ou simplesmente inviabiliza-os. Também são hábeis e astutos em pressionar os governos para receberem o perdão das dívidas. Francisco de Oliveira definia estes empresários como vanguarda do atraso e atraso da vanguarda. É esta minoria supermilionária, do passado e do presente, que quando minimamente ameaçados em seus interesses organizam-se para apoiar e sustentar ditaduras e golpes. O último foi em agosto de 2016.

4 A postura insensata e genocida que estes empresários estão apoiando, insensíveis à clara possibilidade de um aumento exponencial de mortes que podem ser evitadas, explicita-se na cópia da campanha publicitária feita na cidade de Milão - Milão não para -, mesmo depois que o prefeito desta metrópole pediu desculpas pelo erro. Milão contabiliza o maior número de mortes das mais de 11 mil ocorridas até hoje na Itália.

Por fim, fica claro na atitude dos que arquitetaram a campanha no seio do governo, dos empresários que a financiaram e dos que a apoiam uma regressão às teses absurdas do malthusianismo do final do século XVIII e meados do século XIX. O suposto de Malthus era de que a produção da comida crescia em escala aritmética e a população em escala geométrica. Por outro lado, condenava as políticas de assistência aos pobres no combate às pragas e epidemias, pois de acordo com ele era aconselhável nas cidades "construir as ruas mais estreitas, apinhar mais gente no interior das casas e provocar o retorno das pragas. No campo, deveríamos construir as aldeias perto de poços de água estagnados e, sobretudo, encorajar o estabelecimento de colonos em terrenos pantanosos e insalubres" (MALTHUS, apud HUNT; SHERMAN, 1986, p. 64-65). A sua conclusão é de que deste modo a natureza faria uma seleção natural e permitiria que os filhos da elite se casassem muito cedo e tivessem quantos filhos quisessem.

6 A história mostrou que a dificuldade não é a falta de produção de alimentos. Há até superprodução, como mostra Jean Ziegler, consultor da ONU. O problema é que esta produção não está na lógica de satisfazer a necessidade elementar de comer, mas na ordem do lucro e, portanto, para quem pode comprar. $O$ argumento de que vai faltar comida se os indivíduos não voltarem ao trabalho é falso. Onde estão os estoques de um país celeiro e um dos maiores produtores de carnes do mundo? Por outro lado, os cientistas, os médicos, os enfermeiros e todos os representantes da área da Saúde não 
estão solicitando que o país pare por seis meses, mas apenas por um período, para que não haja um colapso do sistema de saúde e possam salvar vidas.

$\mathrm{O}$ argumento do governo e dos empresários que financiaram a campanha o Brasil não pode parar é o mesmo de Malthus. Deixem que o vírus se espalhe, morrerão os que têm doenças crônicas e os mais velhos. $\mathrm{O}$ que os cientistas estão dizendo, inclusive o Ministério da Saúde, é que, se não for feito o controle, não haverá leitos para todos, e milhares morrerão por falta de aparelhos hospitalares suficientes para atendê-los. Os mais afetados serão os pobres das grandes metrópoles, apinhados em favelas. A campanha foi interrompida oficialmente pela Justiça, mas corre nas redes sociais. O que ela afirma é: não importa quantos irão morrer, o que importa é salvar a economia. 0 que não se diz é: os lucros do patronato mais poderoso e rico e do capital financeiro.

Uma semana de panelaços em todo país, a emocionante solidariedade das comunidades pobres, a atitude da maioria dos governadores e prefeitos e uma nova consciência coletiva mostraram que o Brasil, assim como o mundo, não poderá ser mais o mesmo. 0 grafite estampado num muro em Hong Kong - "Não podemos voltar ao normal, porque o normal era exatamente o problema" - aplica-se perfeitamente ao atual governo e aos financiadores da campanha que nos dizem que a vida não importa, mas sim os lucros.

9 E o que significa para nós a lição radical que a Covid-19 nos traz? Primeiro, entender que a guinada que o mundo deu no final da década de 1970, regredindo ao mais radical conservadorismo econômico com o retorno à tese da soberania do mercado, que se firmou na literatura como neoliberalismo, não encontra mais nenhuma sustentação sem que haja uma maior e global destruição de vidas no curto e longo prazo.

O historiador Eric Hobsbawm (1995), em seu clássico livro A era dos extremos - o curto século XX (1914-19790), sublinha que no período em que o Estado e a sociedade regularam o mercado e o capital, o capitalismo viveu sua era de ouro. E esta regulação foi a estratégia dos intelectuais orgânicos do capital para salvar o sistema capitalista. A Primeira Guerra Mundial (1914-19180), seguida de uma revolução socialista na Rússia (1917) e o tsunami da quebra da Bolsa de Nova York (1929) indicavam que o dogma do livre mercado expressava o sentido de uma saciedade de tipo natural, que tenderia ao equilíbrio, caiu por terra. É neste contexto que as análises de John Maynard Keynes delinearam os fundamentos teóricos e políticos da necessidade da estatização dos setores estratégicos da economia (bancos, para ter controle da moeda; energia; riquezas naturais; telecomunicações; infraestrutura de estradas; portos; aeroportos; saneamento básico; habitação; emprego; saúde; educação públicas etc.). As teses de Keynes ganharam prática no Plano Marshall com um programa de recuperação econômica da Europa, destroçada pela Segunda Guerra Mundial (1939-1945). O desdobramento destas teses prevaleceu, como lembra Hobsbawm, em pouco mais de duas dezenas de nações que se pautaram pelo Estado de bem-estar social. Esta digressão histórica nos leva a destacar dois aspectos a serem considerados no que nos atormenta no presente.

11 O primeiro, que o capital, como uma força voraz, sempre buscou escapar dos controles que limita-os à possibilidade de mais lucro e mais concentração de propriedade privada e riqueza. Daí que as teses do conservadorismo do livre mercado permaneceram hibernadas, especialmente as do ferrenho opositor de Keynes, o alemão Friedrich Hayek e seus seguidores. Com efeito, em seu livro 0 caminho da servidão, publicado em 1944, sustentava que as políticas públicas atentavam contra o espírito competitivo 
deformando a natureza, cuja consequência seria a servidão (HAYEK, 1987). As teses de Hayek prevaleceram a partir do final da década de 1970

O segundo aspecto é o que se denominou de "guerra invisível", protagonizada pela Covid-19, que atinge todo o planeta, pela segunda vez põe por terra a doutrina do livre mercado como algo que deriva da própria natureza humana. Ou seja, um ser humano, que, por sua natureza, busca o bom, o útil, o agradável e faz da competição a mola do desenvolvimento pessoal e social. Um raciocínio ideológico que apaga a história humana cindida em classes e que, portanto, essa forma societária resulta da ação dos próprios seres humano e não da natureza.

o que se espera neste tempo histórico é que, no mínimo, como passo elementar, se retorne a visão do controle pela sociedade, mediada por um Estado democrático, do mercado e dos lucros do capital, mormente o financeiro. Trata-se de uma total inversão da direção privatista conservadora ou neoconservadora de sociedade. Inversão que implica o fundo público ampliado para garantir direitos universais e investimento na produção de bens úteis à vida ou da economia real e não a fictícia do mundo financeiro. Um processo que exige rever a lógica de privatizar os setores estratégicos e os bens comuns e a liquidação dos serviços e trabalhadores públicos.

Trata-se pura e simplesmente de copiar o passado? Certamente não, mas de aprender com ele no que degradou e violentou a humanidade, e o que implica, no presente, a ser retomado e ir além, pois o tempo histórico é outro. E aqui entra uma questão central que diz respeito à apropriação privada da ciência e da tecnologia e do direito ao trabalho. Desde o início da primeira "revolução" industrial, a ciência e a tecnologia, bens comuns produzidos socialmente, foram sendo apropriadas privadamente. Assim, elas, cujo valor de uso amplia membros e sentidos humanos e podem qualificar a vida humana e reduzir a jornada de trabalho, converteram-se em arma de controle do trabalhador, intensificação do trabalho e ampliação da exploração, e como corolário do desemprego tecnológico crescente no mundo. Como pode explicar-se que uma multinacional que produz remédios, com base em conhecimentos historicamente produzidos, apenas porque chegou antes a uma fórmula, possa colocar um preço absurdo, como é o caso de remédios para determinado tipo de câncer que podem custar mil reais por dose diária?

Em longa entrevista, concedida ao jornalista italiano Antonio Polito, no final da última década do século XX, sobre as perspectivas do novo século Hobsbawm coloca os efeitos da apropriação privada da ciência e da tecnologia, o que se torna um ponto central na disputa do futuro da classe trabalhadora. "A grande novidade é que, de todos os fatores de produção, os seres humanos são cada vez menos necessários. E o motivo é que, em termos relativos, eles não produzem tanto quanto custam. Os seres humanos não foram criados para o capitalismo. E isso não ocasiona efeitos negativos obre a produção" (HOBSBAWM, 1999, p. 98). Por isto ele argumenta que o problema não é a produção, mas a distribuição. $\mathrm{E}$ o mercado não fará isto.

Pois bem, o único modo eficiente que conhecemos é a redistribuição da riqueza por intermédio do Estado e das autoridades públicas. (...) Não estou dizendo que cabe ao Estado, em sua forma atual, realizar a distribuição, mas que esta precisa ser garantida por algum tipo de autoridade pública. O que acontecerá se isso não ocorrer? Esta é uma questão à qual o fim do século XX já nos proporciona algumas indicações (Ibid. p. 98-99). e o trabalho, cujo efeito, como ele anota, de um lado, estava a realidade de um 
assombroso volume de riqueza na mão de $1 \%$ da população mundial e, de outro, o aumento mundial da pobreza. Disto se depreende que, com muito mais razões, tem que se postular a função social da ciência, da tecnologia e propriedade, a limitação do lucro e sua taxação progressiva. Por essa razão, a questão da ampliação geométrica do fundo público e de seu controle e manejo passam a ser central para o futuro da maior parte dos seres humanos em qualquer sociedade. Como lembrava Francisco de Oliveira, criar esta capacidade social, por certo ainda não é sociedade sem classes, mas pode ser a porta de entrada do socialismo.

Nota-se que o tamanho do desafio planetário é monumental, mas também a oportunidade de criar, como é o slogan dos Fóruns Sociais Mundiais, outro mundo possível. Mas voltando à particularidade brasileira, em que não conhecemos o Estado de bem-estar social, mas a reiteração histórica de uma produção societária de "mal-estar social", valendo-me da expressão de Eduardo Galeano em referência à América Latina, o desafio é extraordinariamente maior. Henri Lefebvre indica que o que restringe um tempo e lugar históricos são os limites sociais da classe dominante. "A verdade e o conhecimento objetivo continuarão incompletos, 'abstractos' e 'unilaterais', enquanto uma classe, historicamente, não tiver senão objetivos limitados, aspirações e fins restritos (LEFEBVRE, 1966, p. 45) 3 .

O que sinalizamos acima sobre os megaempresários brasileiros indica que vivemos numa sociedade onde os limites da classe dominante se fundam em aspirações e objetivos ultrarrestritos, marcados por relações sociais selvagens, predatórias, com fins patrimonialista. Relações que reiteram a violência, no campo e na cidade, sustentadas por leis que protegem os ricos e por ditaduras e golpes. Os dados da Forbes que indicam que, em 2019, houve no Brasil um aumento de 19 bilionários expressa o resultado do golpe de Estado de 2016, com as contrarreformas já mencionas e, por acréscimo, a eleição de um bloco de poder de extrema direita que as tem levado ao extremo.

O comportamento do atual governo, dos grupos empresariais que o sustentam e dos que o apoiam, diante do drama humano causado pela Covid-19, está espantando o mundo da ciência e o mundo político. Nada a comparar. Um boco de poder ( ainda que não homogêneo) mas que dentro do qual prevalecem os fundamentalismos político, religioso e econômico. Sob o fundamentalismo político, pauta-se a pedagogia do ódio com a estratégia de eliminar adversários ou o pensamento crítico. Mediante o fundamentalismo religioso o desprezo à ciência e sua subordinação à crença. Este tem um efeito perverso diante da gravidade do Convid-19. A tese da "gripezinha" do presidente da república expressa a sínteses destes dois fundamentalismos. Sob o fundamentalismo econômico tem-se o mercado ou "a economia" como centro. Disto decorre a insistência do não isolamento com o argumento que isto vai colapsar a economia e os empregos. Para tanto se usa de expedientes mentirosos nas redes sociais, tais como o desabastecimento ou a possível paralisação dos caminhoneiros. A bem da verdade este expediente é utilizado pelo núcleo que aqui denomino de ideológico metafísico. So o aspecto científico diferente tem sido a postura de outros setores, mormente da saúde, agricultura e, até mesmo do ministério da economia.

Este tempo de quarentena, no prazo necessário para vencer a batalha contra o vírus, assim entendido pela maioria dos povos do mundo e, certamente o brasileiro, guarda uma possibilidade sem precedentes em nossa história de estabelecer um marco de ruptura sem retorno com a "normalidade" que nos conduziu até aqui. o grau e ritmo desta ruptura não permitem voluntarismos ou saltos no vazio do campo da ação 
política. E isto vale, sobretudo, para o campo da esquerda nas suas diferenciações internas, como analisa Norberto Bobbio (1994). Trata-se, no patamar básico de mudanças, de uma tarefa para um campo muito mais amplo da esquerda. Destaco, neste sentido, uma indicação precisa de Antônio Gramsci para a análise das forças sociais, presentes em nossa realidade, para nos mover no campo da ação política. "É o problema das relações entre estrutura e superestrutura que deve ser posto com exatidão para que se possa chegar a uma justa análise das forças que atuam na história de um determinado período e determinar a relação entre elas" (GRAMSCI, 2012).

Lúcio Magri, com a expressão "Genoma Gramsci", sinaliza que ele foi o intelectual militante que melhor entendeu os desafios políticos e culturais de seu tempo histórico e que nos deixou bases teóricas que nos servem tanto para analisar a natureza e complexidade dos processos revolucionários quanto as mudanças dentro da ordem burguesa contra esta mesma ordem. A síntese de Magri das indicações de Gramsci nos parece balizar a amplitude das forças sociais que necessitamos para os embates políticos na disputa de novas relações sociais, econômicas e culturais no Brasil de agora em diante.

Para Gramsci, portanto, a revolução representa um longo processo mundial, por etapas, no qual a conquista do poder estatal, ainda que necessária, intervém em certo momento, de acordo com as condições históricas, e no Ocidente pressupõe um longo trabalho de conquista de casamatas, a construção de um bloco histórico entre classes diferentes, cada qual portadora não apenas de interesses diversos, mas de raízes culturais e políticas próprias. Ao mesmo tempo, esse processo social não constitui o resultado gradual e unívoco de uma tendência inscrita no desenvolvimento capitalista e na democracia, mas, ao contrário, é o produto de uma vontade organizada e consciente que intervém no processo de uma nova hegemonia política e cultural, de um novo tipo de ser humano em formação progressiva (MAGRI, 2014. p. 56).

Uma síntese que engendra elementos cuja riqueza e complexidade não podemos extrair neste breve texto. Mas, de imediato, para barrar, no prazo mais curto possível, o atual bloco de poder de extrema direita e anular o conjunto de contrarreformas que aniquilam a esfera pública e os direitos da classe trabalhadora, impõe-se ao campo de esquerda "um longo trabalho de conquista de casamatas, a construção de um bloco histórico entre classes diferentes, cada qual portadora não apenas de interesses diversos, mas de raízes culturais e políticas próprias"

De modo simultâneo, certamente não partimos do zero, mas de um acúmulo histórico da luta de classes para construir de forma ampliada "uma vontade organizada e consciente que intervém no processo de uma nova hegemonia política e cultural, de um novo tipo de ser humano em formação progressiva". Esta formação progressiva de um novo ser humano dá-se no conjunto das relações sociais, culturais, artísticas e, com certeza, nos exige quebrar o processo de dominação que tem como projeto a negação ao conhecimento cientifico para a maioria da população brasileira. Aqui a luta nos cobra erradicar no curto prazo o analfabetismo e universalizar acesso a creches e Ensino Básico públicos, sob novas bases materiais (prédios, espaços, laboratórios, bibliotecas, tempo integral para professores, técnicos e demais trabalhadores do chão da escola, salários dignos) e sob uma concepção pedagógica de formação omnilateral (intelectual, psíquica, física, estética). Não por acaso a classe dominante brasileira tem como projeto, hoje explícito, barrar esta conquista. 

que estamos descobrindo nas relações familiares e com as demais pessoas, a produção de ideias fecundas para desenvolver um processo social, político e cultural que mostre, no médio e longo prazo, a capacidade da revolução que necessitamos para erradicar a desigualdade e, com ela, a pobreza. Para confrontar os limites, a ignorância, o cinismo dos empresários bilionários e do conjunto da classe burguesa de que fazem parte, finalizo este breve texto com o que sublinha Raymond Willians na tarefa de construção de uma nova hegemonia.

“(...) sei que há um trabalho fundamental a ser feito em relação à hegemonia cultural. Acredito que o sistema de significados e valores que a sociedade capitalista gera tem de ser derrotado geral e no detalhe por meio de um trabalho intelectual e educacional contínuo. (...) temos de aprender e ensinar uns aos outros as conexões que existem entre formação política e econômica e, talvez, mais difícil, formação educacional e formação de sentimentos e de relações, que são os nossos recursos em qualquer forma de luta" (2007, p. 15).

Uma indicação que capta o sentido da tarefa educativa que nos cabe como intelectuais pesquisadores e educadores do campo da esquerda e à esquerda no seu conjunto. Tarefa que, na nossa diversidade de visões políticas, não pode perder nunca a grandeza de sentimentos e as relações de fraternidade.

\section{BIBLIOGRAFIA}

BOBBIO, Norberto. Direita e esquerda. Raízes de uma distinção política. São Paulo: Companhia das Letras, 1994.

FERNANDES, Florestan. A revolução burguesa no Brasil. Ensaio de interpretação sociológica. Rio de Janeiro: Zahar Editores, 1974.

GRAMSCI, Antônio. In: COUTINHO, Carlos Nelson (editor); NOGUEIRA, Marco Aurélio; HENRIQUES, Luiz Sérgio (coeditores). Antonio Gramsci. Cadernos do Cárcere. v.3, 5. ed. Rio de Janeiro, Civilização Brasileira, 2012.

HAYEK, Friedrich. O caminho da servidão. Rio de Janeiro: Instituto Liberal, 1987.

HOBSBAWM, Eric. Era dos extremos: o breve século XX, 1914-1991. São Paulo: Companhia das Letras, 1995.

HOBSBAWM, Eric. O novo século. São Paulo: Companhia das Letras, 1999.

LEFEBVRE, Henri. Para compreender o pensamento de Karl Marx. Lisboa: Edições 70, 1966.

MAGRI, Lúcio. O alfaiate de ULM. Uma possível história do Partido Comunista Italiano. São Paulo, Boitempo, 2014.

MALTHUS, Thomas. In. HUNT; SHERMAN. Introdução ao pensamento econômico. Petrópolis, Rio de Janeiro. Editora Vozes, 1986, 5. ed.

PRADO JUNIOR, Caio. A revolução brasileira. São Paulo: Brasiliense, 1966. 
WILLIAMS, Raymond. Palavras-chave - um vocabulário de cultura e sociedade. São Paulo: Boitempo, 2007.

\section{NOTAS}

1. . Este texto é uma versão ampliada do artigo publicado on-line no Jornal Brasil de Fato, em 30/3/2019. Disponível em: https://www.brasildefato.com.br/2020/03/30/artigo-empresariosmais-ricos-do-brasil-ignorancia-cinismo-e-ganancia-que-matam.

2. . Disponível em: https://exame.abril.com.br/negocios/brasil-ganha-novos-bilionarios-vejaquem-sao-os-20-mais-ricos/. Acesso em: 31 mar. 2010.

3. Sobre a formação da classe burguesa brasileira e sua estratégia reiterada de contrarreformas, para se manter seus privilégio, ver Fernandes (1974).

\section{RESUMOS}

$\mathrm{O}$ artigo analisa aspectos da formação histórica da burguesia empresarial brasileira, identificando as práticas econômicas, políticas e sociais subjacentes ao padrão de participação na acumulação capitalista constituído ao longo dessa formação, bem como os valores e comportamentos que se vinculam a essas práticas e as reanimam em diferentes contextos. A superexploração e a espoliação do trabalhador e da natureza, bem como a relação utilitária e desdenhosa com a ciência, dentre outros aspectos, são analisados como elementos constitutivos de uma subjetividade que, no contexto de eclosão mundial da gravíssima pandemia de Covid-19, manifesta-se no apoio irresponsável a políticas desumanas que, para preservar formas egoístas e lesivas de produção e apropriação econômica, não hesitam em descartar vidas.

El artículo analiza aspectos de la formación histórica de la burguesía empresarial brasileña, identificando las prácticas económicas, políticas y sociales subyacentes al patrón de participación en la acumulación capitalista constituida a lo largo de esta formación, así como los valores y comportamientos que están vinculados a estas prácticas y revivirlos en diferentes contextos. La sobreexplotación y la expoliación del trabajador y la naturaleza, así como la relación utilitaria y desdeñosa con la ciencia, entre otros aspectos, se analizan como elementos constitutivos de una subjetividad que, en el contexto de la eclosión mundial de la pandemia extremadamente grave de Covid-19, se manifiesta en un apoyo irresponsable a políticas inhumanas que, para preservar formas de producción y apropiación económica egoístas y dañinas, no duden en descartar vidas.

Cet article reprend les pratiques économiques, politiques et sociaux concernant à la formation historique de la bourgeoisie brésilienne, ainsi qu'il souligne les valeurs et les comportements de cette classe sociale réanimés selon différents contextes. La surexploitation et la spoliation des ouvriers et de la nature, liées à une relation dédaigneuse et utilitaire devant la science, sont analysées à l'intérieure d'une subjectivité dont les politiques économiques inhumaines au nom de la plus-value sont les résultats les plus perverses - y compris l'élimination de la vie face aux défis de la Covid-19. 
The article analyzes aspects of historical formation of Brazilian bourgeoise, identifying the economic, political and social practices underlying the pattern of participation in capitalist accumulation constituted throughout this formation

as well as the values and behaviors that are linked to these practices and revive them in different contexts. Overexploitation and the plundering of workers and nature, just as the utilitarian and disdainful relationship with science among other aspects, they are analyzed as constitutive elements of a subjectivity that, in the context of the worldwide outbreak of the extremely serious pandemic of Covid-19, manifests itself in irresponsible support for inhuman policies that, in order to preserve selfish and harmful forms of production and economic appropriation, do not hesitate to discard lives.

\section{ÍNDICE}

Palavras-chave: concentração de renda, burguesia brasileira, espoliação, acumulação capitalista, empresários

Palabras claves: concentración del ingreso, burguesía brasileña, despojo, acumulación capitalista, empresarios.

Keywords: concentration of income, Brazilian bourgeoisie, spoliation, capitalist accumulation, businessmen

Mots-clés: Covid-19, Brésil, bourgeoisie, capitalisme, néolibéralisme.

\section{AUTOR}

\section{GAUDÊNCIO FRIGOTTO}

Filósofo, pesquisador e educador, professor titular (aposentado) na Universidade Federal Fluminense e, atualmente, professor associado na Universidade do Estado do Rio de Janeiro 